the diagnosis by nearly one day and prompt earlier adequate treatment. Furthermore, we showed that meningococci are still present in skin lesions of patients with sepsis several hours after the start of antimicrobial treatment. Immediate administration of antibiotics by the first doctor considering a diagnosis of meningococcal sepsis will therefore not disturb proper diagnosis. Finally, the finding of diplococci in Gram stained skin lesions in a patient with meningitis may warn the clinician of possible deterioration.

Seventy six years after Gram negative diplococci were described in skin lesions by Netter and Salanier we can still endorse the statement of Hill and Kinney made 30 years later: "it is surprising that biopsy as a diagnostic adjunct has not gained more widespread recognition." ${ }^{23}$

1 Apicella MA. Neisseria meningitidis. In: Mandell GL, Douglas RG, Bennett $\mathrm{JE}$, eds. Principles and practice of infectious diseases. New York: Churchill Livingstone, 1990: 1600-13.

2 Halstensen A, Pedersen SHJ, Haneberg B, Bjorvatn B, Solberg CO. Case fatality of meningococcal disease in Western Norway. Scand $\mathcal{f}$ Infect Dis 1987;19:35-42.

3 Cahalane SF, Waters $M$. Fulminant meningococcal septicaemia. A hospital experience. Lancet 1975;ii:120-1.

4 McGehee WG, Rapaport SI, Hjort PF. Intravascular coagulation in fulminant meningococcemia. Ann Intern Med 1967; 67:250-60.

5 Mercier J-C, Beaufils F, Hartmann J-F, Azéma D. Hemodynamic patterns of meningococcal shock in children. Crit Care Med 1988;16:27-34.

6 Giraud T, Dhainaut J-F, Schremmer B, Regnier B, Desjars P, Loirat P, et al. Adult overwhelming meningococcal purpura. A study of 35 cases, Adult overwhelming meningococcal purpura.

7 NIklasson P-M, Lundbergh P, Strandell T. Prognostic factors in meningococcal disease. Scand I Infect Dis 1971;3:17-25.

8 Manios SG, Kanakoudi F, Maniati E. Fulminant meningococcemia. Heparin therapy and survival rate. Scand $\mathcal{F}$ Infect Dis 1971;3:127-33.

9 Emperanza JI, Aldamiz-Echevarria L, Perez-Yarza EG, Larranăa P, Jiminez $\mathrm{JL}$, Labiano M, et al. Prognostic score in acute meningococcemia. Crit Care Med 1988;16:168-9.

10 Netter A, Salanier $M$. The presence of meningococci in the purpuric elements of meningococcal infection. British fournal of Children's Diseases 1917;14: 101-4.

11 Netter A, Salanier $M$, Blanchier $M$. Two fresh cases of meningococcal infection with presence of meningococcus in the purpuric eruption: cultivation of the meningococcus from the serum of a vesicle in one of the cases; occurrence of a strain of meningococci differeing from the typical meningococcus. British fournal of Children's Diseases 1917;14:264-6.

12 McLean S, Caffey J. Endemic purpuric meningococcus bacteremia in early life: the diagnostic value of smears from the purpuric lesions. Am $f$ Dis Child 1931;42:1053-74

13 Tompkins VN. The diagnostic value of smears from purpuric lesions of the skin in meningococcic disease. $f A M A 1943 ; 123: 31-2$.
14 Bernhard WG, Jordan AC. Purpuric lesions in meningococcic infections. Diagnosis from smears and cultures of the purpuric lesions. $7 \mathrm{Lab}$ Clin Med 1944;29:273-81.

15 Waage A, Brandzaeg P, Halstensen A, Kierulf P, Espevik T. The complex pattern of cytokines in serum of patients with meningococcal septic shock. Association between interleukin 6, interleukin 1, and fatal outcome. $\mathcal{J}$ Exp Med 1989;169:333-8.

16 Van Deuren M, Santman FW, Van Dalen R, Sauerwein RW, Span LFR, Van der Meer JWM. Plasma and whole blood exchange in meningococcal sepsis. Clin Infect Dis 1992;15:424-30.

17 Sinclair JF, Skeoch CH, Hallworth D. Prognosis of meningococcal septicaemia. Lancet 1987;ii:38.

18 Bone RC, Fisher CJ, Clemmer TJ, Slotman GJ, Metz GA, Balk RA, et al. Sepsis syndrome: a valid clinical entity. Crit Care Med 1989;17:389-93.

19 Toews WH, Bass JW. Skin manifestations of meningococcal infection. An immediate indicator of prognosis. Am $\mathcal{F}$ Dis Child 1974;127:173-6.

20 Brandtzaeg P, Dahle JS, Høiby EA. The occurrence and features of hemorrhagic skin lesions in 115 cases of meningococcal disease. NIPH Ann 1983;6:183-90, 202-3

21 Rubenstein R, Esterley NB. Meningococcal meningitis with a benign skin rash. Pediatr Dermatol 1986;3:414-6.

22 Baxter P, Priestley B. Meningococcal rash. Lancet 1988;i: 1166-7.

23 Hill WR, Kinney TD. The cutaneous lesion in acute meningococcemia. fAMA 1947;134:513-8.

24 Tonjum T, Nilsson F, Bruun JN, Haneberg B. The early phase of meningococcal disease. NIPH Ann 1983;6:175-81.

25 Dahle JS. Pathogenesis of hemorrhagic skin lesions in meningococcal disease. NIPH Ann 1983;6:49-53.

26 Davis CE, Arnold K. Role of meningococcal endotoxin in meningococcal purpura. $f$ Exp Med 1974;140:159-71.

27 Movat HZ, Burrowes CE. The local Shwartzman reaction: endotoxinmediated inflammatory thrombo-hemorrhagic lesions. In: Berry LJ, ed. Handbook of endotoxin. Vol 3. Cellular biology of endotoxin. Amsterdam: Elsevier, 1985:260-302.

28 Argenbright LW, Barton RW. Interactions of leucocyte integrins with intercellular adhesion molecule 1 in the production of inflammatory vascular injury in vivo. 7 Clin Invest 1992;89:259-72.

29 Hoyne AL, Brown RH. 727 Meningococcic cases: an analysis. Ann Intern Med 1948;28:248-59.

30 Talan DA, Hoffman JR, Yoshikawa TT, Overturf GD. Role of empiric parenteral antibiotics prior to lumbar puncture in suspected bacterial meningitis: state of art. Rev Infect Dis 1988;10:365-76.

31 Gedde-Dahl TW, Høiby EA, Eskerud JR. Unbiased evidence on early treatment of suspected meningococcal disease. Rev Infect Dis 1990;12: 359-63.

32 Kilpi T, Anttila M, Kallio MJT, Peltola H. Severity of childhood bacterial meningitis and duration of illness before diagnosis. Lancet 1991;ii:406-9.

33 Strang JR, Pugh EJ. Meningococcal infections: reducing the case fatality rate by giving penicillin before admission to the hospital. $B M \mathcal{F}$ 1992;305:141-7.

34 Begg N. Reducing mortality from meningococcal disease. BMf 1992;305: 133-4.

35 Tomplins LS. The use of molecular methods in infectious diseases. $N$ Engl $f$ Med 1992;327:1290-7.

36 Haolin NI, Knight AI, Cartwright K, Palmer WH, McFadden J. Polymerase chain reaction for diagnosis of meningococcal meningitis. Lancet 1992;ii: $1432-4$.

(Accepted 2 March 1993)
Tayside Health Board, Dundee DD1 9NL

Trevor Smith, information services officer

$B M F$ 1993;306:1232-5

\title{
Influence of socioeconomic factors on attaining targets for reducing teenage pregnancies
}

Trevor Smith

Abstract

Objective-To determine the rate of pregnancy and outcome in teenagers in areas of different socioeconomic conditions, and to assess the implication for achievement of government and local targets in reducing unwanted pregnancies in teenagers.

Design-Records of pregnancies were obtained from hospital discharge files and rates of live and still births and abortions calculated for each postcode sector. Postcodes were grouped by categories of deprivation and by local government district. Setting-Tayside, Scotland.

Subjects-Teenage girls admitted to National Health Service hospitals for delivery or abortion in 1980-90.

Main outcome measures-Conception in girls aged under 16 by area of residence and relative proportion leading to live births or terminations. Rate of different outcomes in girls under the age of 20 by area of residence.

Results-The pregnancy rate in girls aged under 16 was three times as high, and in all girls under 20 six times as high in the most deprived areas as in the most affluent areas. The proportion of teenage pregnancies ending in abortions was higher in the affluent areas, where two out of three ended in abortion compared with one out of four in the deprived areas.

Conclusions-Although there was a higher pregnancy rate in teenagers in more deprived areas, the proportion ending in abortion was greater in more affluent areas, possibly due to social and parental pressure. The wide geographical variation in patterns of teenage pregnancy indicates the need for a small area rather than a regional approach to setting targets and devising measures of achieving them.

\section{Introduction}

In its white paper The Health of the Nation the government set a target for reducing the conception rate in girls aged under 16 by at least $50 \%$ by the year 2000 from the 1989 figure of 9.5 per 1000 girls aged 13 to 15 to no more than $4 \cdot 8$ per $1000 .^{1}$ Although it would be wrong to assume that all pregnancies in these girls 
are unwanted, a high proportion (52\% in England and Wales in 1989) end in legal abortion, indicating that many clearly are. ${ }^{2}$ While the equivalent Scottish Office publication Scotland's Health, a Challenge to Us All failed to set such a target, many health authorities in Scotland will wish to set comparable targets of their own.

I determined current trends in teenage pregnancies in Tayside and the extent to which they varied in different parts of the region in relation to the prevailing socioeconomic conditions. I also studied how many of these pregnancies were unwanted (as estimated by the number of legal abortions) and whether unwanted pregnancies followed the same geographical pattern as pregnancies overall. Geographical information of this kind is essential to enable planning decisions to be made about the targeting of resources aimed at reducing the rate of unwanted conceptions.

As these considerations apply equally to teenage pregnancies as a whole and not just to those in girls aged under 16, I conducted parallel analyses for the girls aged under 16 and those aged under 20 .

\section{Subjects and methods}

In Scotland details of episodes of care in maternity hospitals are recorded in a scheme known as the Scottish morbidity record 2. Details of all patients admitted to Tayside hospitals between 1 January 1980 and 31 December 1990 were downloaded from the mainframe at the East Central Computer Consortium in Dundee on to floppy disk and analysed on a local personal computer with dBase IV software. At each stage of the analysis every care was taken to ensure confidentiality and to conform to the principles of the Data Protection Act 1984

Those records in which the outcome code indicated a live birth or stillbirth were selected, the mother's age at conception calculated, and the records of those girls in whom this was less than 16 years were selected for further investigation. In investigations of total pregnancies in girls aged under 20 the age of the girl at the time of the birth or termination was used rather than the date of conception to facilitate comparison with figures from other regions calculated on a similar basis.

Information on abortions was obtained from both the maternity scheme and the scheme for acute inpatient admissions. In the latter the type of abortion was indicated by ICD (ninth revision) codes 630 to 638 .

My figures for legal abortions do not distinguish between those which were carried out for social reasons and those performed because of risk to the life of the woman or abnormality of the fetus. As fewer than $1 \%$ of abortions in Tayside are carried out for these latter reasons, however, no effort was made to separate them. ${ }^{4}$ To show the effect of socioeconomic conditions on rates of pregnancy I allocated each girl's postcode sector of residence to one of seven deprivation categories. The categories were those devised by Carstairs and Morris based on the following four variables derived from the 1981 census: 1 -the percentage of men who were unemployed; 2 -the percentage of people in social classes IV and V; 3-the percentage of the population with no car; and 4-the percentage of the population in overcrowded housing. ${ }^{5}$ In an additional study postcodes were also grouped into local authority districts.

A Lotus 1-2-3 spreadsheet was created, containing a list of the 70 Tayside postcode sectors used in the analysis, with their corresponding deprivation category and local government district. Data relating to all births and abortions were inserted for each sector and population figures added for the calculation of rates. Insertion of target numbers of conceptions in specific postcode sectors enabled the effect on the overall Tayside target to be assessed.

Girls who had had more than one pregnancy before the age of 20 were identified by their unique health board community health index numbers, the index being a register of everyone registered with a general practitioner in Tayside or otherwise known to the region's health service.

\section{Results}

PREGNANCIES IN GIRLS AGED UNDER 16

During the 1980 s the rate of conception in girls aged under 16 was three times higher in the most deprived areas of Tayside than in the most affluent (table I). The deprived areas, however, had a lower proportion of pregnancies ending in abortion-one in two compared to two in three in the most affluent areas. The overall conception rate in the whole of Tayside and the proportion ending in abortion changed little over the decade.

As well as the clear variations in conception rates detected by deprivation analysis considerable variations also occurred between Tayside's three local government districts. At 11.6 conceptions per 1000 girls aged 13 to 15 the annual rate in Dundee district was twice that in Perth and Kinross (5.4 per 1000), with Angus lying in between (8.3 per 1000).

The data in table II emphasise the importance of ensuring in any reports or papers dealing with pregnancies in young girls that readers are told whether the figures relate to maternal age at conception or to age at the outcome of the pregnancy. Between 1980 and 1990 $40 \%$ of the girls who conceived before their 16 th birthday did not give birth or have their pregnancy terminated until after they were 16 . This was particularly true for those girls who kept their babies; two out of three who conceived before their 16th birthday did not give birth until after they were 16 .

\section{ALI TEENAGE PREGNANCIES}

As in girls who conceived under the age of 16 , the overall rate of teenage pregnancies increased dramatically from the most affluent to the most deprived areas of Tayside. Table III shows that throughout the 11 years studied the rate was four to eight times higher in the most deprived postcode sectors than in the most

TABLE I-Outcome of pregnancies in girls conceiving before the age of 16 resident in Tayside 1980 to 1990 by socioeconomic conditions. Figures are average annual rates per 1000 girls

\begin{tabular}{lcccc}
\hline $\begin{array}{l}\text { Deprivation } \\
\text { category* }\end{array}$ & $\begin{array}{c}\text { Girls aged } \\
\text { 13-15 years } \dagger\end{array}$ & $\begin{array}{c}\text { Live births and } \\
\text { stillbirths }\end{array}$ & $\begin{array}{c}\text { Legal } \\
\text { abortions }\end{array}$ & $\begin{array}{c}\text { Total } \\
\text { pregnancies }\end{array}$ \\
\hline 7 & 607 & $8 \cdot 8$ & $9 \cdot 1$ & $18 \cdot 3$ \\
6 & 672 & $7 \cdot 3$ & $7 \cdot 3$ & $15 \cdot 0$ \\
5 & 1323 & $5 \cdot 4$ & $6 \cdot 9$ & $12 \cdot 7$ \\
4 & 1461 & $3 \cdot 2$ & $5 \cdot 5$ & $8 \cdot 8$ \\
3 & 1516 & $1 \cdot 8$ & 3.9 & $5 \cdot 8$ \\
2 & 1811 & 1.5 & $2 \cdot 8$ & $4 \cdot 6$ \\
1 & 589 & $1 \cdot 2$ & $3 \cdot 9$ & $5 \cdot 2$ \\
\hline All areas & 7979 & 3.5 & $5 \cdot 1$ & 8.9
\end{tabular}

*7=Most deprived; 1 = most affluent.

tAverage of the 1981 census population and 1990 Tayside community health index estimate.

TABLE II-Age at conception compared with age at delivery or abortion in Tayside hospitals, ${ }^{\star} 1980$ to 1990

\begin{tabular}{lrrrrr}
\hline & $\begin{array}{c}\text { Age at conception in girls who } \\
\text { gave birth or had abortion } \\
\text { before age of } 16\end{array}$ & $\begin{array}{c}\text { No who conceived } \\
\text { at } 15 \text { and gave birth } \\
\text { or had abortion at }\end{array}$ \\
\cline { 2 - 6 } Outcome of pregnancy & 13 & 14 & 15 & $13-15$ & 16 \\
\hline Live and stillbirths & 0 & 13 & 83 & 96 & 219 \\
Legal abortions & 14 & 83 & 285 & 382 & 104 \\
Spontaneous abortions & 0 & 3 & 14 & 17 & 8 \\
\hline All pregnancies & 14 & 99 & 382 & 495 & 331 \\
\hline
\end{tabular}


affluent. The socioeconomic difference in the rate of abortion was, however, much less pronounced than that affecting the rate of live births. Table IV illustrates the remarkable rise in the proportion of teenage pregnancies which end in abortion in moving from the deprived to the affluent areas. In the most deprived postcode sectors around one in four pregnancies ended in abortion compared with around two in three in the most affluent sectors.

The picture was similar when each of the three local government districts were looked at individually. Within a district rates of teenage pregnancies were highest in the most deprived postcode sectors; conversely, the more affluent the area the higher the proportion of such pregnancies ending in abortion.

None of the deprivation categories showed a particularly clear increase or decrease in rates of teenage pregnancies over the 11 years.

\section{REPEAT TEENAGE PREGNANCIES}

Between 1980 and 1990 I identified 1075 girls who had had two pregnancies as teenagers. Table $\mathrm{V}$ shows the pattern of outcomes associated with these pregnancies. Eighteen per cent of the girls (193) were married on both occasions, and almost all of these (175) had two live births, with none terminating both pregnancies.

Of girls who were recorded as "single" at the end of

TABLE II-Pregnancies in teenagers * by socioeconomic conditions in area of residence, Tayside 1980 to 1990

\begin{tabular}{|c|c|c|c|c|c|c|c|}
\hline \multirow{2}{*}{$\begin{array}{l}\text { Deprivation } \\
\text { categoryt }\end{array}$} & \multirow{2}{*}{$\begin{array}{l}\text { Girls aged } \\
15-19 \text { at } \\
\text { April } 1981 \neq\end{array}$} & \multirow{2}{*}{$\begin{array}{c}\text { Girls aged } \\
15-19 \text { at } \\
\text { July } 1990 \ddagger\end{array}$} & \multicolumn{4}{|c|}{ Annual average rate per 1000 girls aged 15 to 19} & \multirow{2}{*}{$\begin{array}{c}\text { Average annual No of } \\
\text { pregnancies in } \\
\text { teenagers } 1980-90\end{array}$} \\
\hline & & & $1980-2$ & $1983-5$ & $1986-8$ & $1989-90$ & \\
\hline 7 & 1401 & 867 & 128 & 124 & 185 & 135 & 161 \\
\hline 6 & 1431 & 1102 & 80 & 75 & 106 & 103 & 113 \\
\hline 5 & 3077 & 2265 & 70 & 73 & 88 & 83 & 208 \\
\hline 4 & 2886 & 2524 & 50 & 52 & 58 & 57 & 147 \\
\hline 3 & 2852 & 2597 & 42 & 40 & 45 & 49 & 118 \\
\hline 2 & 3195 & 3287 & 35 & 32 & 32 & 32 & 106 \\
\hline 1 & 1020 & 980 & 21 & 30 & 22 & 23 & 24 \\
\hline All areas & 15862 & 13622 & 57 & 57 & 64 & 60 & 877 \\
\hline
\end{tabular}

All areas average annual number of pregnancies

$903 \quad 900 \quad 869 \quad 821$
877

*Includes live births and stillbirths, therapeutic abortions, and all kinds of spontaneous abortions occurring before girls' 20 th birthday entailing admission to hospital.

girls' 20 th birthday entailing admission
$\dagger 7=$ Most deprived; $1=$ most affluent.

$\$ 1981$ Census population figures were used for $1980-2$ and $1983-5$ denominators; population at July 1990 derived from Tayside community health index used for years 1986-8 and 1989-90.

TABLE IV-Legal abortions as a percentage of total teenage pregnancies*

\begin{tabular}{|c|c|c|c|c|c|}
\hline $\begin{array}{l}\text { Deprivation } \\
\text { categoryt }\end{array}$ & $1980-2$ & $1983-5$ & $1986-8$ & $1989-90$ & $\begin{array}{c}\text { Average annual No of } \\
\text { abortions in teenagers } \\
1980-90\end{array}$ \\
\hline $\begin{array}{l}7 \\
6 \\
5 \\
4 \\
3 \\
2 \\
1\end{array}$ & $\begin{array}{l}27 \cdot 2 \\
36 \cdot 3 \\
28 \cdot 9 \\
40 \cdot 0 \\
45 \cdot 8 \\
47 \cdot 7 \\
64 \cdot 1\end{array}$ & $\begin{array}{l}24 \cdot 8 \\
32 \cdot 3 \\
32 \cdot 4 \\
41.9 \\
44 \cdot 7 \\
47 \cdot 4 \\
66.0\end{array}$ & $\begin{array}{l}23.9 \\
28.3 \\
32 \cdot 1 \\
37 \cdot 6 \\
47 \cdot 6 \\
49 \cdot 8 \\
60 \cdot 6\end{array}$ & $\begin{array}{l}29 \cdot 1 \\
33 \cdot 3 \\
31 \cdot 0 \\
41 \cdot 3 \\
47 \cdot 8 \\
54 \cdot 0 \\
62 \cdot 2\end{array}$ & $\begin{array}{l}42 \\
37 \\
65 \\
59 \\
55 \\
52 \\
16\end{array}$ \\
\hline All areas & $36 \cdot 7$ & 36.9 & $36 \cdot 0$ & $39 \cdot 3$ & 325 \\
\hline
\end{tabular}

TABLE V-Sequence of births and legal abortions in girls having two pregnancy outcomes before age of 20 in Tayside 1980 to 1990

\begin{tabular}{|c|c|c|c|c|c|c|}
\hline \multicolumn{2}{|c|}{ Outcome sequence } & \multicolumn{5}{|c|}{ Marital state at first and second pregnancies } \\
\hline $\begin{array}{l}\text { First } \\
\text { pregnancy }\end{array}$ & $\begin{array}{l}\text { Second } \\
\text { pregnancy }\end{array}$ & $\begin{array}{l}\text { Single for } \\
\text { both }\end{array}$ & $\begin{array}{l}\text { Single then } \\
\text { married }\end{array}$ & $\begin{array}{l}\text { Married then } \\
\text { single }\end{array}$ & $\begin{array}{l}\text { Married for } \\
\text { both }\end{array}$ & All states \\
\hline $\begin{array}{l}\text { Live }^{\star} \\
\text { Live }^{\star} \\
\text { Abortion } \\
\text { Abortion }\end{array}$ & $\begin{array}{c}\text { Live* } \\
\text { Abortion } \\
\text { Live^ } \\
\text { Abortion }\end{array}$ & $\begin{array}{l}225 \\
148 \\
187 \\
142\end{array}$ & $\begin{array}{r}81 \\
6 \\
68 \\
2\end{array}$ & $\begin{array}{r}9 \\
12 \\
0 \\
2\end{array}$ & $\begin{array}{r}175 \\
16 \\
2 \\
0\end{array}$ & $\begin{array}{l}490 \\
182 \\
257 \\
146\end{array}$ \\
\hline \multicolumn{2}{|c|}{ All outcomes } & 702 & 157 & 23 & 193 & 1075 \\
\hline
\end{tabular}

*Includes stillbirths. both pregnancies $32 \%$ (225) had live births (or stillbirths) on both occasions compared with $20 \%$ (142) terminating their pregnancies on both occasions. Of those single girls who had terminated their first pregnancy $57 \%$ (187) kept their baby on the second occasion.

I also identified 136 girls over the same period who had had three pregnancies as teenagers, 12 who had had four, and one who had had five. Sixteen per cent of the girls having three pregnancies gave birth to three live babies whereas only $6 \%$ terminated all three of their pregnancies.

\section{Discussion}

PREGNANCIES IN GIRLS AGED UNDER 16

The choice of the Carstairs index for measuring deprivation was based on its well established ability to discriminate within Scotland in general and Tayside in particular between areas with different health and behavioural patterns. ${ }^{58}$ In the most affluent areas of Tayside (deprivation categories 1 and 2) the government's target of no more than 4.8 conceptions per 1000 girls aged 13 to 15 by the year 2000 has nearly been achieved. These areas contain around $30 \%$ of the population of girls in this age group. This contrasts with the most deprived areas (deprivation categories 6 and 7 ), comprising $16 \%$ of the relevant population, in which the rate of conception is currently three times above the target. This fact, together with the clear differences between local government districts in Tayside, clearly emphasises the need for measures aimed at reducing the incidence of teenage pregnancies to be targeted on specific geographical areas.

As I included known spontaneous abortions in my analysis, the number of pregnancies in the under $16 \mathrm{~s}$ that I recorded would be about 3\% higher than the equivalent calculations from the Office of Population Censuses and Surveys.

\section{ALL TEENAGE PREGNANCIES}

The outcomes of pregnancies in girls up to the age of 20 showed a similar pattern to those in girls aged under 16 , with the rate of pregnancies increasing dramatically from the most affluent to the most deprived postcode sectors. The larger numbers enabled trends over time to be examined in small areas. The slight fall observed between 1980 and 1990 in the absolute numbers of teenage pregnancies was due to the declining teenage population; the rate per 1000 girls remained steady or increased slightly. This compares with an increase in the rate of teenage conceptions in England of 9\% between 1979 and $1989 .{ }^{2}$

The especially sharp decline observed during the decade in the population of girls in some of the deprived postcode sectors emphasises the importance of having a local means of estimating the population of small areas between the national censuses, which are done every 10 years. The existence in Tayside Health Board of the community health index fulfils this need.

The exclusion from my figures of home births and of abortions performed on Tayside residents outside Tayside is unimportant as these account for no more than $0.5 \%$ of the total births and $1.0 \%$ of the abortions respectively. ${ }^{4}$ Less than $2 \%$ of legal abortions in Scotland are performed outside NHS hospitals. ${ }^{4}$ These were not included.

A consistent observation in each year of the study was the remarkable difference in the proportion of pregnancies which ended in abortion in different geographical areas. Whereas in the most deprived areas one out of four girls terminated their pregnancies in the most affluent areas two out of three did so. As all of the abortions were carried out in NHS hospitals, ability to pay was not a factor in the socioeconomic difference. 
These results agree with a recent observation that the proportion of teenage pregnancies aborted is much higher in the prosperous south eastern regions of England than in the northern regions. ${ }^{6}$

As in the English study, the differences within Tayside did not seem to be related to the availability of abortions on the National Health Service. Geographically most of the deprived areas are closer to the two hospitals where most abortions were carried out than are the affluent areas. Moreover, the rate of teenage abortions in Tayside is higher than the Scottish average, ${ }^{4}$ and facilities are generally considered to meet the demand.

It is not known how many of the girls recorded as resident in the deprived areas had moved there from more affluent areas to have their babies as a result of changed relationships with parents and boyfriends arising from their pregnancy. A recent analysis of previous addresses on the community health index, however, suggests that this was probably not an important factor in their high rate of live births. Out of a sample of 31 girls living in the most deprived areas (deprivation category 7) when they gave birth in 1992, 23 were at the same address before the start of their pregnancies, and those who moved there during pregnancy all came from the same or other deprived areas (categories 5 and 6). Neither is it possible to say whether a higher proportion of the girls resident in the deprived areas who become pregnant were in stable relationships than of those girls in the affluent areas because of the decline in recent years in the popularity among teenagers of an official marriage ceremony; in 1980 some 9029 teenage girls got married in Scotland compared with only 2285 in $1990 .^{7}$ In my analysis of girls who had had two pregnancies as teenagers the high proportion of single girls who kept both of their babies suggests that many were in fact in stable relationships despite the designation.
The current unreliability of the term "single" when applied to marital status in young people emphasises the need for an additional option to be included in all record systems to distinguish between people who are genuinely single and those in a stable relationship but not officially married.

For girls who are genuinely single having a child, whether planned or unplanned, may be more socially acceptable in the deprived areas than in the more affluent areas. This raises the worrying question of whether girls in the most affluent areas are placed under undue social and parental pressure to terminate their pregnancies, possibly against their real wishes.

In terms of absolute numbers of girls involved (rather than rates) the problem of unwanted teenage pregnancies as measured by abortions is clearly as much one of affluent areas as deprived areas.

The need to reduce the risk of unwanted pregnancy has assumed greater urgency in recent years because of the concomitant risk of contracting HIV (against which the morning after pill offers no defence), and thus the problem of preventing unwanted conceptions in the under $16 \mathrm{~s}$, in teenagers as a whole, and indeed in all age groups has to be urgently addressed.

\section{Secretary of State for Health. The health of the nation; a strategy for health in England. London: HMSO, 1992. (CM 1986.) \\ 2 OPCS. Birth Statistics 1990, 19. London: HMSO, 1992 \\ 3 The Scottish Office. Scotland's health, a challenge to us all. Edinburgh: HMSO, 1992. \\ 4 Information and Statistics Division, Common Services Agency. Scottish health statistics. Edinburgh: ISD Publications, 1991. \\ 5 Carstairs V, Morris R. Deprivation and health in Scotland. Aberdeen: Aberdeen University Press, 1991. \\ 6 Wilson SH, Brown TP, Richards RG. Teenage conceptions and contraception in the English Regions. Fournal of Public Health Medicine 1992;14:17-25. \\ 7 General Register Office for Scotland. Annual repon of the registrar general for Scotland 1990. No 136. Edinburgh: HMSO, 1991. \\ $8 \mathrm{Smith} \mathrm{T}$. The relative effects of sex and deprivation on the risk of premature} death. Foumal of Rublic Health Medicine 1992;14:402-7.
Microalbuminuria Collaborative Study Group Members of the study group are listed at the end of the paper.

Correspondence to: Dr Jeannie Yip, Unit for Metabolic Medicine, United Medical and Dental Schools, Guy's Hospital, London SE1 9RT.

BMY 1993;306:1235-9

\title{
Risk factors for development of microalbuminuria in insulin dependent diabetic patients: a cohort study
}

\author{
Microalbuminuria Collaborative Study Group, United Kingdom
}

\section{Abstract}

Objective-To investigate the risk factors for the development of persistent microalbuminuria in insulin dependent diabetic patients.

Design-Four year follow up of a cohort of diabetic patients.

Setting-Outpatient departments of teaching and district general hospitals in England.

Subjects-148 non-microalbuminuric, nonhypertensive insulin dependent diabetic patients.

Main outcome measures-Urinary albumin excretion rate and arterial blood pressure.

Results-137 patients completed four year follow up, of whom 11 developed persistent microalbuminuria (albumin excretion rate $\geqslant 30 \mu \mathrm{g} / \mathrm{min}$ on at least two consecutive occasions), giving a cumulative frequency of $8 \% .103$ remained normoalbuminuric and 23 exhibited intermittent microalbuminuria. At baseline the persistent microalbuminuric group had had significantly raised blood pressure (mean 137.9 (SD 14.9)/82.3 (7.6) v 123.5 (13.2)/72.8 (9.1) mm Hg), glycated haemoglobin concentration $10.4 \%(2.0 \%) v$ $8-9 \%(2 \cdot 0 \%)$, and albumin excretion rate (median (interquartile range) $17.5(13 \cdot 0-22 \cdot 3) v 0.8$ (3.7-6.7) $\mu g / m i n)(p<0.05$ for all) compared with the normoalbuminuric group. Blood pressure and glycated haemoglobin remained significantly higher in the persistent microalbuminuric group throughout the study $(p<0.05)$. Multiple regression analysis showed initial albumin excretion rate, blood pressure, and smoking to be significant determinants of persistent microalbuminuria $(p<0.02)$.

Conclusion-In insulin dependent diabetic patients with poor glucose control, which may initially increase albumin excretion rate, an early rise of arterial pressure and smoking are implicated in the development of persistent microalbuminuria.

\section{Introduction}

The reasons for the susceptibility to nephropathy of a subset of insulin dependent diabetic patients remain elusive. The two clinical hallmarks of overt diabetic kidney disease are persistent proteinuria and arterial hypertension.

Microalbuminuria, an early marker of progression to overt renal disease in insulin dependent diabetes, ${ }^{1-4}$ has been found to be associated with poor glycaemic control $^{5}$ and raised arterial pressure. ${ }^{245}$ Changes in these variables seem to occur in parallel in microalbuminuric patients, ${ }^{6}$ but the cause-effect relation between them is unclear and the factors responsible for 